\title{
Gene of the month: H3F3A and H3F3B
}

\author{
Alessandro Pietro Aldera (ㄷ) 1,2 Dhirendra Govender (i) 2,3
}

${ }^{1}$ Anatomical Pathology, JDW Pathology Inc, Cape Town, South Africa

${ }^{2}$ Division of Anatomical Pathology, University of Cape Town, Cape Town, South Africa ${ }^{3}$ Anatomical Pathology, Pathcare, Cape Town, South Africa

\section{Correspondence to} Dr Alessandro Pietro Aldera, JDW Pathology Inc, Cape Town, 7405, South Africa; aaldera@ gmail.com

Accepted 1 November 2021 Published Online First 15 November 2021

\begin{abstract}
H3F3A and H3F3B genes are located at $1 \mathrm{q} 42.12$ and 17q25.1, respectively, and encode identical H3.3 core histone proteins which form part of the histone heterooctamer complex. Histones function by packaging DNA into small units, the nucleosome, and are highly susceptible to epigenetic post-translational modification. H3 K27 mutations have been shown to inhibit the polycomb repressive complex 2 , which is normally involved in epigenetic gene silencing. Mutations in $H 3 F 3 A$ and $H 3 F 3 B$ are increasingly recognised in a variety of solid tumours. Point mutations in H3F3A have been described in giant cell tumour of bone and paediatric-type diffuse high-grade gliomas. Mutations in H3F3B have been described in chondroblastoma. Loss of trimethylation of $\mathrm{H} 3 \mathrm{~K} 27$ is characteristic of most sporadic and radiation-associated malignant peripheral nerve sheath tumours. Immunohistochemistry with a variety of novel antibodies directed against specific mutations, as well as loss of H3K27me3 staining, may be useful in specific settings and in diagnostically challenging cases.
\end{abstract}

\section{INTRODUCTION}

Histones are nuclear proteins that maintain the nucleosome structure of chromatin in eukaryotic organisms. ${ }^{1} \mathrm{H} 3$ is one of the four core histone proteins which comprise the histone heterooctamer, around which approximately 147 base pairs of DNA wrap to form the nucleosome. ${ }^{2}$

\section{GENE AND PROTEIN STRUCTURE}

In mammals, the $\mathrm{H} 3$ family includes the canonical replication-dependant $\mathrm{H} 3.1$ and $\mathrm{H} 3.2$, and the replication-independent variant $\mathrm{H} 3.3 .^{3} \mathrm{H} 3 \mathrm{~F} 3 \mathrm{~A}$ and $H 3 F 3 B$ encode identical conserved $\mathrm{H} 3.3$ histone proteins (figure 1) which differ only in their mRNA untranslated regions and regulatory sequences. ${ }^{4} \mathrm{H} 3 \mathrm{~F} 3 \mathrm{~A}$ is located on chromosome $1 \mathrm{q} 42.12$ and comprises seven exons. ${ }^{5}$ H3F3B occurs on chromosome $17 \mathrm{q} 25.1$ and comprises four exons. ${ }^{5}$ Both H3F3A and H3F3B genes contain introns and their mRNAs and are polyadenylated, unlike the genes encoding the canonical H3.1 and H3.2 histone proteins. ${ }^{6}$ The H3.3 protein consists of a 136-amino acid sequence with a molecular weight of $15.328 \mathrm{kDa}^{7}$ The structure of the core histones is predominantly globular, other than their $\mathrm{N}$-terminus tail portions which are unstructured. The histone hetero-octamer consists of a tetramer $\mathrm{H} 3-\mathrm{H} 4$ complex flanked by two $\mathrm{H} 2 \mathrm{~A}-\mathrm{H} 2 \mathrm{~B}$ dimers.

\section{PHYSIOLOGICAL FUNCTION}

Histones compact DNA into the fundamental unit of chromatin, the nucleosome, while still enabling the cellular processes operating on DNA to occur. These processes include transcription, DNA repair, DNA replication and chromatin condensation. Histone function is modulated by at least eight covalent posttranslational modifications including acetylation, phosphorylation and methylation. ${ }^{8}$ Another manner by which nucleosomes are controlled is the incorporation of histone variant proteins into the heterooctamer complex. Histone variant $\mathrm{H} 3.3$ differs from the canonical $\mathrm{H} 3$ proteins $(\mathrm{H} 3.1$ and $\mathrm{H} 3.2)$ in that its incorporation onto chromatin is cell cycle independent (ie, occurring throughout the cell cycle and not S-phase dependent) and mediated by the chaperone complexes histone regulator A (HIRA) and the death-associated protein $(\mathrm{DAXX}) / \alpha$-thalassaemia X-linked mental retardation protein (ATRX). ${ }^{9}{ }^{10} \mathrm{H} 3.3$ is enriched in genomic regions showing 'active' transcription, pericentromeric and telomeric regions. ${ }^{6}{ }^{11}$ H3 K27 mutations have been shown to inhibit the polycomb repressive complex 2 (PRC2), which is normally involved in epigenetic gene silencing. ${ }^{12}$

\section{ROLE IN DISEASE}

Mutations in $H 3 F 3 A$ and $H 3 F 3 B$ genes are increasingly recognised in a variety of tumours ranging from indolent bone tumours to highly aggressive brain tumours (table 1 ).

\section{Chondroblastoma}

Chondroblastoma is an uncommon benign tumour of bone, typically occurring in skeletally immature long bones. The femur, proximal tibia and proximal humerus are the sites most commonly affected. The age range is $10-25$ years and males are twice as likely to be affected. ${ }^{13}$ These tumours occur adjacent to the growth plate, typically involving the epiphysis or epiphysis and metaphysis as welldefined radiolucent lesions on plane film imaging. ${ }^{14}$ Histologically, these tumours are composed of sheets of chondroblastic cells with distinct cell borders, grooved nuclei and dispersed osteoclastlike giant cells. ${ }^{15}$ Pericellular chicken-wire calcification is a distinctive feature. In the vast majority of cases, these tumours are cured by surgical curettage. ${ }^{16}$ Recurrence rates vary with the site of disease and are higher in flat and craniofacial bones.

Behjati et al were the first to identify the lysine amino acid substitution p.Lys36Met in 73 of 77 chondroblastomas studied. ${ }^{17}$ This point mutation occurred predominantly in $H 3 F 3 B$ but was also found in a small proportion of cases to occur in H3F3A. These findings have been subsequently 


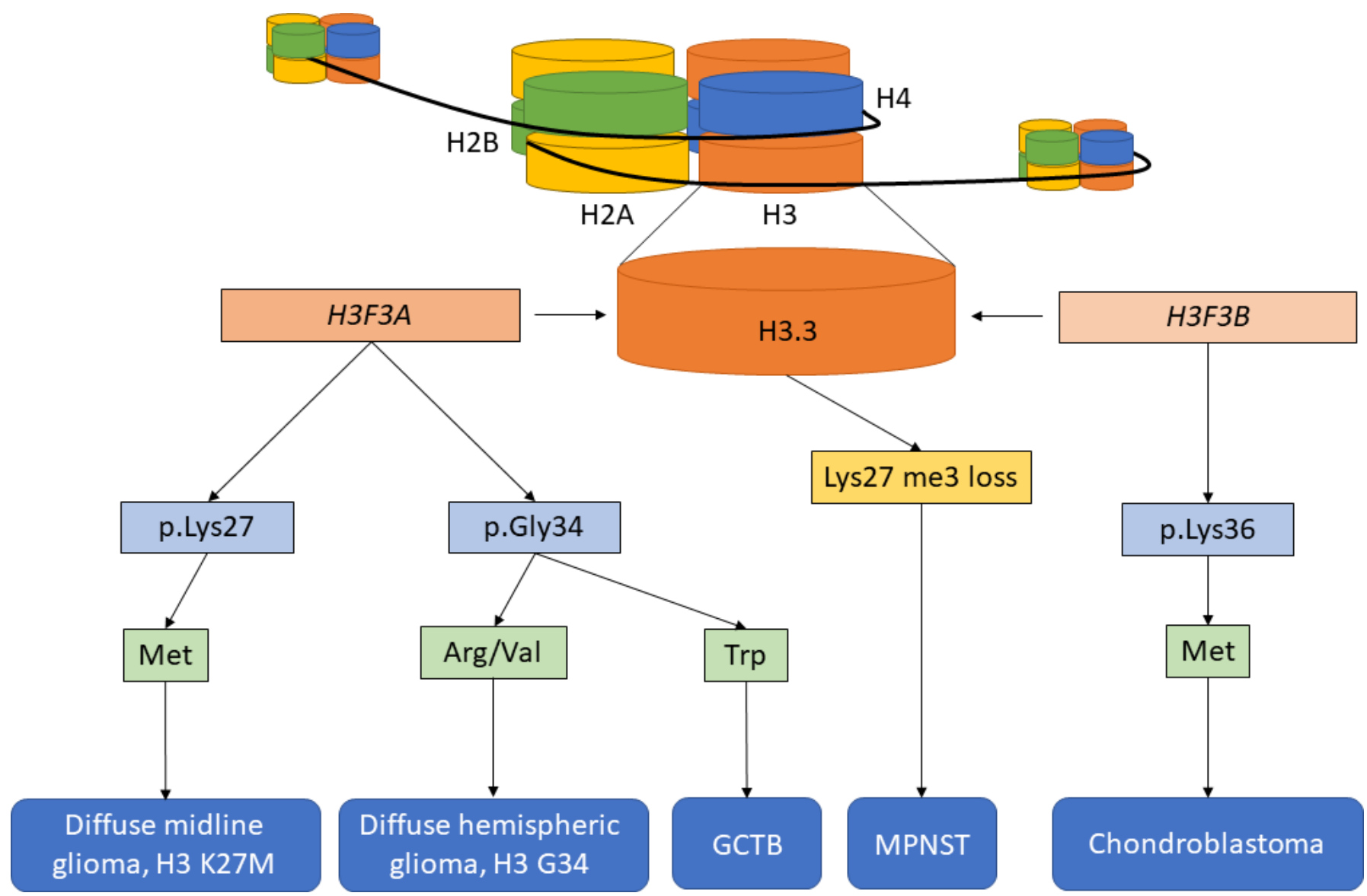

Figure $1 H 3 F 3 A$ and $H 3 F 3 B$ genes encode identical H3.3 proteins. Point mutations at key amino acid residues give rise to diverse tumours. This infogram highlights the most common point mutations and associated tumours. GCTB, giant cell tumour of bone; MPNST, malignant peripheral nerve sheath tumour.

confirmed by other groups. ${ }^{18}$ Immunohistochemistry with the H3 K36M mutant antibody shows nuclear positivity in $>96 \%$ of cases and is of particular value in limited biopsies or cases with extensive aneurysmal bone cyst-like change. ${ }^{19-21}$

\section{Giant cell tumour of bone (GCTB)}

GCTB is a locally aggressive and rarely metastasising neoplasm which has a similar anatomical distribution to chondroblastoma but typically occurs in skeletally mature individuals. The peak incidence is between the ages of 20 and 45 years. ${ }^{22}$ Microscopically, GCTB comprises sheets of mononuclear cells which may be round to oval in shape, or spindled when associated with a fibrous matrix, with conspicuous numbers of osteoclast-like giant cells. Secondary changes may obscure the typical morphology

Table 1 Tumours associated with H3.3 aberrations

\begin{tabular}{|c|c|c|c|}
\hline & Mutation & Gene & Immunohistochemistry \\
\hline Chondroblastoma & p.Lys36Met & $\begin{array}{l}\text { H3F3B }(95 \%) \\
\text { H3F3A }(5 \%)\end{array}$ & H3 K36M \\
\hline Giant cell tumour of bone & p.Gly34Trp & H3F3A & H3 G34W \\
\hline $\begin{array}{l}\text { Diffuse midline glioma, } \\
\text { H3 K27-altered }\end{array}$ & p.Lys27Met & $\begin{array}{l}\text { H3F3A } \\
\text { HIST1H3B/C }\end{array}$ & H3 K27M \\
\hline $\begin{array}{l}\text { Diffuse hemispheric } \\
\text { glioma, H3 G34-mutant }\end{array}$ & p.Gly34Arg/Val & H3F3A & H3 G34R/V \\
\hline $\begin{array}{l}\text { Malignant peripheral } \\
\text { nerve sheath tumour }\end{array}$ & $\begin{array}{l}\text { Loss of } \\
\text { trimethylation }\end{array}$ & $\begin{array}{l}\text { EED } \\
\text { SUZ12 }\end{array}$ & H3K27me3 (loss) \\
\hline
\end{tabular}

and make diagnosis more challenging. These include necrosis, fresh haemorrhage, collections of macrophages, haemosiderin deposition, aneurysmal cyst change and deposition of fibrous tissue or bone. GCTB may metastasise to the lung. Malignant GCTB is uncommon and characterised by a nodule of pleomorphic mononuclear cells occurring in an otherwise conventional GCTB. GCTB treated with the monoclonal antibody targeting the key bone resorption mediator RANKL, denosumab, may show abundant new bone formation, bland spindled cells and depletion of the osteoclast-like giant cells. ${ }^{23}$

Approximately 95\% of GCTBs harbour recurrent mutations in H3F3A. These are most commonly amino acid substitutions involving a glycine residue (p.Gly34Trp). Less common point mutations that have been described include p.Gly34Leu, p.Gly34Met, p.Gly34Arg and p.Gly34Val. Immunohistochemistry with a monoclonal antibody directed against the $\mathrm{H} 3$ Gly34Tryp point mutation (G34W) has a high sensitivity and specificity. $^{2425}$ Yamamoto et al found H3 G34W expression in all the recurrent, metastatic, post-treatment (denosumab) and secondarily malignant GCTB. ${ }^{25}$

\section{Paediatric-type diffuse high-grade gliomas}

Diffuse midline glioma, H3 K27-altered, is defined as a highgrade infiltrative neoplasm which occurs in the midline, shows predominantly astrocytic differentiation and harbours distinctive mutations in $\mathrm{H} 3$. This is the new terminology proposed in the upcoming fifth edition WHO Blue Book as it has become 
increasingly clear that alternative mechanisms can result in alteration of the pathogenic pathway in these tumours. ${ }^{26}$ Historical designations have included 'brainstem glioma' or 'diffuse intrinsic pontine glioma'. These tumours occur predominantly in children and have a very poor prognosis. The 2-year survival is less than $10 \%$ despite current best therapies. In these tumours, the traditional morphological features used to grade glial neoplasms (mitoses, necrosis and microvascular proliferation) are not reliable. Sequencing studies have identified the recurrent heterozygous mutation p.Lys27Met (K27M) affecting H3F3A or HIST1H3B/C (encoding H3.1). ${ }^{27}$ Mutations in H3F3A are about three times as prevalent as those in $H I S T 1 H 3 B / C$.

H3 K27M immunohistochemistry can be used to identify tumours harbouring $\mathrm{K} 27 \mathrm{M}$ mutations with high sensitivity and specificity and minimal intratumoural heterogeneity. ${ }^{28}$ Nuclear staining is regarded as positive, and care must be taken to disregard non-specific cytoplasmic staining, which may be seen in macrophages and glial cells. The H3K27me3 antibody (decreased protein expression interpreted as a surrogate marker for H3 K27M) may be used as a screening method to identify cases, but interpretation is often challenging due to non-specific staining of inflammatory cells, endothelial cells and glial tissue. ${ }^{28}$

Diffuse hemispheric glioma, H3 G34-mutant (DHG) is a newly recognised brain tumour which typically occurs in the cerebral hemispheres of teenagers and young adults, and generally has a more favourable prognosis than glioblastoma, isocitrate dehydrogenase (IDH)-wildtype and diffuse midline glioma, H3 K27-altered. ${ }^{29}$ This is still, however, a WHO grade 4 tumour. Histologically, these tumours are heterogeneous and may resemble high-grade gliomas or primitive neuroepithelial tumours. DHG is genetically defined by a recurrent point mutation, p.Gly34Arg/Val (G34R/V), occurring in H3F3A. Mutantspecific antibodies for H3 G34R and H3 G34V are commercially available and have been found to show a high degree of sensitivity and specificity for DHG. ${ }^{30}$

\section{Malignant peripheral nerve sheath tumour}

Malignant peripheral nerve sheath tumour (MPNST) is a malignant soft tissue neoplasm which may arise de novo from a pre-existing benign nerve sheath tumour or in the setting of neurofibromatosis type 1 . These tumours have complex karyotypes and frequently show combined inactivation in three pathways NF1, CDKN2A/CDKN2B and PRC2 core components (embryonic ectoderm development (EED) and suppressor of zeste 12 (SUZ12)). ${ }^{31}{ }^{32}$ Mutations in EED and SUZ12 induce loss of trimethylation at lysine 27 of histone 3 (H3K27me3). ${ }^{33}$ Outside of the setting of NF1, the diagnosis of MPNST is often challenging with high interobserver variability and relies on a combination of morphological features, patchy expression of S100 or SOX10 and the demonstration of possible involvement of a nerve structure.

Complete or partial loss of H3K27me3 nuclear expression by immunohistochemistry is highly specific for MPNST. ${ }^{34}{ }^{35}$ The sensitivity of this marker is somewhat modest and almost comparable to staining with S100 protein, ranging from $57 \%$ to $69 \%$. Fortunately, the sensitivity is higher in sporadic cases and those associated with radiotherapy (91\%-95\%), where the diagnosis is often more challenging. ${ }^{34}$ Heterozygous staining or partial loss is demonstrated in a small proportion of cases. Interestingly, loss of $\mathrm{H} 3 \mathrm{~K} 27 \mathrm{me} 3$ is less useful diagnostically in the setting of NF1 occurring in only $60 \%$ of cases. Of note, H3K27me3 expression is retained in epithelioid MPNST.

\section{Developmental and behavioural disorders}

In animal studies, knockout of H3.3 has shown its important role in neurodevelopment and neuromuscular function. ${ }^{36}$ This has not yet been thoroughly investigated in humans. Recently, a group from Slovenia who performed whole exome sequencing on a patient with microcephaly and developmental delay found a missense variant c. $185 \mathrm{~T}>\mathrm{G}$ in $\mathrm{H} 3 \mathrm{~F} 3 \mathrm{~A}$. $^{37}$

\section{Take home messages}

- H3F3A and H3F3B encode identical non-canonical variant H3.3 proteins which form part of the histone hetero-octamer, around which approximately 147 base pairs of DNA wrap to form the nucleosome.

- Histones function to maintain the structure of chromatin and are influenced by a variety of post-translational modifications.

- Point mutations in H3F3A have been described in giant cell tumour of bone and paediatric-type diffuse high-grade gliomas, while point mutations in H3F3B have been described in chondroblastoma.

- Loss of trimethylation of H3 K27 is characteristic of most sporadic and radiation-associated malignant peripheral nerve sheath tumours.

- Immunohistochemistry with antibodies directed against specific mutations as well as H3K27me3 are useful diagnostically.

Handling editor Runjan Chetty.

Contributors The manuscript was prepared by both authors.

Funding The authors have not declared a specific grant for this research from any funding agency in the public, commercial or not-for-profit sectors.

Competing interests None declared.

Patient consent for publication Not applicable.

Provenance and peer review Commissioned; internally peer reviewed.

\section{ORCID iDs}

Alessandro Pietro Aldera http://orcid.org/0000-0002-9615-1692

Dhirendra Govender http://orcid.org/0000-0003-1487-8255

\section{REFERENCES}

1 Bhasin M, Reinherz EL, Reche PA. Recognition and classification of histones using support vector machine. J Comput Biol 2006;13:102-12.

2 McGhee JD, Felsenfeld G. Nucleosome structure. Annu Rev Biochem 1980:49:1115-56

3 Hake SB, Garcia BA, Duncan EM, et al. Expression patterns and post-translational modifications associated with mammalian histone $\mathrm{H} 3$ variants. J Biol Chem 2006:281:559-68.

4 Frank D, Doenecke D, Albig W. Differential expression of human replacement and cell cycle dependent H3 histone genes. Gene 2003;312:135-43.

$5 \mathrm{NCBI}$ Resource Coordinators. Database resources of the National center for biotechnology information. Nucleic Acids Res 2018;46:D8-13.

6 Szenker E, Ray-Gallet D, Almouzni G. The double face of the histone variant H3.3. Cell Res 2011;21:421-34.

7 UniProt Consortium. UniProt: a worldwide hub of protein knowledge. Nucleic Acids Res 2019:47:D506-15.

8 Kouzarides T. Chromatin modifications and their function. Cell 2007;128:693-705.

9 Tagami H, Ray-Gallet D, Almouzni G, et al. Histone H3.1 and H3.3 complexes mediate nucleosome assembly pathways dependent or independent of DNA synthesis. Cell 2004; 116:51-61

10 Goldberg AD, Banaszynski LA, Noh K-M, et al. Distinct factors control histone variant H3.3 localization at specific genomic regions. Cell 2010;140:678-91.

11 Delbarre $\mathrm{E}$, Jacobsen $\mathrm{BM}$, Reiner $\mathrm{AH}$, et al. Chromatin environment of histone variant $\mathrm{H} 3.3$ revealed by quantitative imaging and genome-scale chromatin and DNA immunoprecipitation. Mol Biol Cell 2010;21:1872-84.

12 Lewis PW, Müller MM, Koletsky MS, et al. Inhibition of PRC2 activity by a gain-offunction H3 mutation found in pediatric glioblastoma. Science 2013;340:857-61.

13 Bloem JL, Mulder JD. Chondroblastoma: a clinical and radiological study of 104 cases. Skeletal Radiol 1985;14:1-9 
14 McLeod RA, Beabout JW. The roentgenographic features of chondroblastoma. Am J Roentgenol Radium Ther Nucl Med 1973;118:464-71.

15 Dahlin DC, Ivins JC. Benign chondroblastoma. A study of 125 cases. Cancer 1972:30:401-13.

16 Ebeid WA, Hasan BZ, Badr IT, et al. Functional and oncological outcome after treatment of chondroblastoma with intralesional curettage. J Pediatr Orthop 2019;39:e312-7.

17 Behjati S, Tarpey PS, Presneau N, et al. Distinct H3F3A and H3F3B driver mutations define chondroblastoma and giant cell tumor of bone. Nat Genet 2013:45:1479-82.

18 Fang D, Gan H, Lee J-H, et al. The histone H3.3K36M mutation reprograms the epigenome of chondroblastomas. Science 2016;352:1344-8.

19 Amary MF, Berisha F, Mozela R, et al. The H3F3 K36M mutant antibody is a sensitive and specific marker for the diagnosis of chondroblastoma. Histopathology 2016;69:121-7.

20 Cleven AHG, Höcker S, Briaire-de Bruijn I, et al. Mutation analysis of H3F3A and H3F3B as a diagnostic tool for giant cell tumor of bone and chondroblastoma. Am J Surg Pathol 2015;39:1576-83.

21 Lu C, Ramirez D, Hwang S, et al. Histone H3K36M mutation and trimethylation patterns in chondroblastoma. Histopathology 2019;74:291-9.

22 Al-Ibraheemi A, Inwards CY, Zreik RT, et al. Histologic spectrum of giant cell tumor (GCT) of bone in patients 18 years of age and below: a study of 63 patients. Am J Surg Pathol 2016;40:1702-12.

23 Girolami I, Mancini I, Simoni A, et al. Denosumab treated giant cell tumour of bone: a morphological, immunohistochemical and molecular analysis of a series. J Clin Pathol 2016;69:240-7.

24 Amary F, Berisha F, Ye H, et al. H3F3A (histone 3.3) G34W immunohistochemistry: a reliable marker defining benign and malignant giant cell tumor of bone. Am J Surg Pathol 2017:41:1059-68.

25 Yamamoto $\mathrm{H}$, Iwasaki T, Yamada Y, et al. Diagnostic utility of histone H3.3 G34W, G34R, and G34V mutant-specific antibodies for giant cell tumors of bone. Hum Pathol 2018;73:41-50
26 Sievers $P$, Sill M, Schrimpf D, et al. A subset of pediatric-type thalamic gliomas share a distinct DNA methylation profile, H3K27me3 loss and frequent alteration of EGFR. Neuro Oncol 2021;23:34-43.

27 Buczkowicz P, Hoeman C, Rakopoulos P, et al. Genomic analysis of diffuse intrinsic pontine gliomas identifies three molecular subgroups and recurrent activating ACVR1 mutations. Nat Genet 2014:46:451-6.

28 Bechet D, Gielen GGH, Korshunov A, et al. Specific detection of methionine 27 mutation in histone 3 variants (H3K27M) in fixed tissue from high-grade astrocytomas. Acta Neuropathol 2014;128:733-41.

29 Korshunov A, Capper D, Reuss D, et al. Histologically distinct neuroepithelial tumors with histone $3 \mathrm{G} 34$ mutation are molecularly similar and comprise a single nosologic entity. Acta Neuropathol 2016;131:137-46.

30 Haque F, Varlet P, Puntonet J, et al. Evaluation of a novel antibody to define histone 3.3 G34R mutant brain tumours. acta neuropathol commun 2017:5:1-9.

31 Lee W, Teckie S, Wiesner T, et al. Prc2 is recurrently inactivated through Eed or SUZ12 loss in malignant peripheral nerve sheath tumors. Nat Genet 2014;46:1227-32.

32 Zhang $M$, Wang $Y$, Jones $S$, et al. Somatic mutations of SUZ12 in malignant peripheral nerve sheath tumors. Nat Genet 2014;46:1170-2.

33 Cao R, Wang L, Wang $\mathrm{H}$, et al. Role of histone $\mathrm{H} 3$ lysine 27 methylation in polycombgroup silencing. Science 2002;298:1039-43.

34 Prieto-Granada CN, Wiesner T, Messina JL, et al. Loss of H3K27me3 expression is a highly sensitive marker for sporadic and radiation-induced MPNST. Am J Surg Pathol 2016;40:479-89.

35 Schaefer I-M, Fletcher CD, Hornick JL. Loss of H3K27 trimethylation distinguishes malignant peripheral nerve sheath tumors from histologic mimics. Mod Pathol 2016;29:4-13

36 Maze I, Wenderski W, Noh K-M, et al. Critical role of histone turnover in neuronal transcription and plasticity. Neuron 2015;87:77-94.

37 Maver A, Čuturilo G, Ruml SJ, et al. Clinical next generation sequencing reveals an H3F3A gene as a new potential gene candidate for microcephaly associated with severe developmental delay, intellectual disability and growth retardation. Balkan J Med Genet 2019:22:65-8. 